\title{
Intraoperative Monitoring with Transesophageal Echocardiography in Cardiac Surgery
}

\author{
Carlos Galhardo Júnior, TSA ${ }^{\text {, }}$ Eduardo Souza Leal Botelho ${ }^{2}$, Luis Antonio dos Santos Diego, TSA ${ }^{3}$
}

\begin{abstract}
Summary: Galhardo Jr C, Botelho ESL, Diego LAS - Intraoperative Monitoring with Transesophageal Echocardiography in Cardiac Surgery.
Background and objectives: Since its clinical introduction in the 80s, intraoperative transesophageal echocardiography (TEE) has represented one of the greatest advances in modern cardiac anesthesia. It is a semi-invasive technique that allows direct and fast visualization of structural anatomy of the heart and great vessels as well as contributes to hemodynamic and functional evaluation of the cardiovascular system. Thus, it has become an important monitor in aiding the diagnosis of cardiac pathologies and anesthesia and surgical interventions. The objective of this report was to perform a comprehensive review on the use of intraoperative TEE in cardiac surgery.
\end{abstract}

Contents: This article reviews some aspects of ultrasound physics, imaging techniques, echocardiographic cuts used more oftenly, indications, and main clinical applications in addition to contraindications and complications.

Conclusions: Intraoperative TEE is a safe method of cardiovascular monitoring, which is useful in the formulation of a surgical strategy, orientation of hemodynamic interventions, and immediate assessment of surgical outcomes. Once qualified to use the method, the anesthesiologist expands its role in perioperative medicine, providing clinical information necessary to the anesthetic-surgical procedure in cardiac surgery.

Keywords: Echocardiography, Transesophageal; Cardiac Surgical Procedures; Intraoperative Care.

[Rev Bras Anestesiol 2011;61(4): 495-512] @Elsevier Editora Ltda.

\section{INTRODUCTION}

The introduction of transesophageal echocardiography (TEE) in the operating room represented a great advance in cardiovascular monitoring and is routinely used in several cardiac surgery centers. This technique allows direct and fast visualization of the structural anatomy of the heart and large vessels, and contributes to the hemodynamic and functional assessment of the cardiovascular system. In recent years, with the improvement in generation of acoustic images resolution and portability of equipment, TEE has become an important method for early diagnosis of myocardial ischemia, adjustment of valve repairs and exchanges, determination of acute hemodynamic disorders, and diagnosis of pathologies

Received from the Instituto Nacional de Cardiologia - INC, Brazil.

1. Coordinator of the Serviço de Anestesia de Adulto of INC

2. Anesthesiologist of INC and UERJ

3. Professor of Universidade Federal Fluminense; Ph.D. Anesthesiologist UNESP, Botucatu, - SP; Regent of Núcleo de Ensino e Pesquisa da Divisão de Anestesia of INC

Submitted on June 27, 2010.

Approved on December 13, 2010.

Correspondence to:

Dr. Carlos Galhardo Júnior

Rua John Kennedy, 424, apto. 101

Barra da Tijuca

22620-260 - Rio de Janeiro, RJ, Brazil

E-mail: cgalhardo@uol.com.br not identified in the preoperative period. Obtaining real time information allows the surgeon to correct inadequate repairs and prevent or treat surgical complications before the patient leaves the operating room therefore reducing the need of reoperations. Due to its benefits TEE has had an increasingly important role in modern cardiac surgery.

The first report on the use of echocardiography during a surgical procedure dates back to 1972 when an epicardial probe was used to evaluate the results of a mitral comissurotomy ${ }^{1}$. In the early 80 s with the transesophageal probe development Matsumoto et al. ${ }^{2}$ began using echocardiography for continuous intraoperative assessment of the left ventricular function. In the late 80s TEE was benefited by the incorporation of color flow image associated with high-resolution transducers. Since then there were several advances in ultrasound technology such as multiplane and multi-frequency probes, digital image processing, and more recently the use of tissue Doppler and tridimensional (3D) image acquisition ${ }^{3,4}$. With these advances the number of intraoperative TEE clinical applications has grown and spread widely. In 1993 Seward et al. ${ }^{5}$ reported one of the first systematic approaches of transesophageal echocardiography with a multiplane probe.

Several reports have shown the positive impact of using this technique in defining surgical strategy, assessment of operative results, and orientation of anesthetic management ${ }^{6-9}$. Minhaj et al. ${ }^{10}$, through a prospective clinical investigation of 283 patients undergoing cardiac surgeries, observed that the routine use of TEE revealed new pathologic findings (previously unidentified) in one in every 3 patients, and in $25 \%$ of the cases it led to a change in surgical approach. In their preli- 
minary data Fanshawe et al. ${ }^{11}$ suggested that routine use of TEE in cardiac surgeries is beneficial, reduces patient morbidity, and is cost-effective.

With the increasing use of TEE in the operating room anesthesiologists have sought training and competence to effectively use this method therefore widening its activities in the context of perioperative medicine. In Brazil, intraoperative transesophageal echocardiography in cardiac surgeries is still incipient, restricted to some centers that have an expressive number of surgeries. The basic prerequisites for this technique proper use and interpretation include: study of cardiac anatomy and physiology, understanding the basic physical principles of the ultrasound, acquisition of technical ability to obtain images, proper interpretation of these images, correlating them with the hemodynamic status of patient, as well as appropriate knowledge of the indications, contraindications, and limitations of the method. Some guidelines for training, certification, and improvement of perioperative echocardiography have been published by several societies of anesthesiology 12-14.

\section{BASIC ULTRASOUND PRINCIPLES}

Ultrasound waves are mechanically-induced vibrations that produce compressions and rarefactions of molecules in a given medium. They are defined as acoustic waves beyond the capacity of detection by the human ear, i.e., above $20 \mathrm{KHz}$. Ultrasound used in medicine emit frequencies of 1 to $20 \mathrm{MHz}$. Available TEE probes are in the $5-7 \mathrm{MHz}$ range.

Transesophageal echocardiography is performed with an endoscopic probe (Figure 1) equipped with an ultrasound transducer on its tip, and it has a command system that allows one to direct the ultrasound beam to cardiac structures after being positioned in the esophagus or stomach. Sound frequencies are sent into the thoracic cavity and undergo interactions with tissues. These interactions are based on ultrasound wave reflection, dispersion, refraction, and/or attenuation. The ultrasound image is related to reflection (echo) of the waves transmitted to tissues. The ability of ultrasound wave reflection is determined by the difference in acoustic impedance between tissues and the insonation angle in relation to the structure examined. An optimal ultrasound reflection is seen with a perpendicular angle $\left(90^{\circ}\right)$. Tissue acoustic impedance results from its density and propagation velocity in the tissue ${ }^{15}$. The greater the difference between tissue densities stronger the reflection of sound waves. The amount of sound produced by this reflection is received by the transducer, amplified, processed, and translated into images on the monitor. Ultrasound transducers use piezoelectric crystals as transmitters and receptors of high-frequency sound waves. They are quartz crystals with the ability to change their conformation and vibrate when submitted to an electric current producing ultrasound waves ${ }^{16}$.

In 1842 the Austrian physicist Johan C. A. Doppler described in his book Über das farbige Licht der Doppelsterne one of the physical principles used more often in medicine,

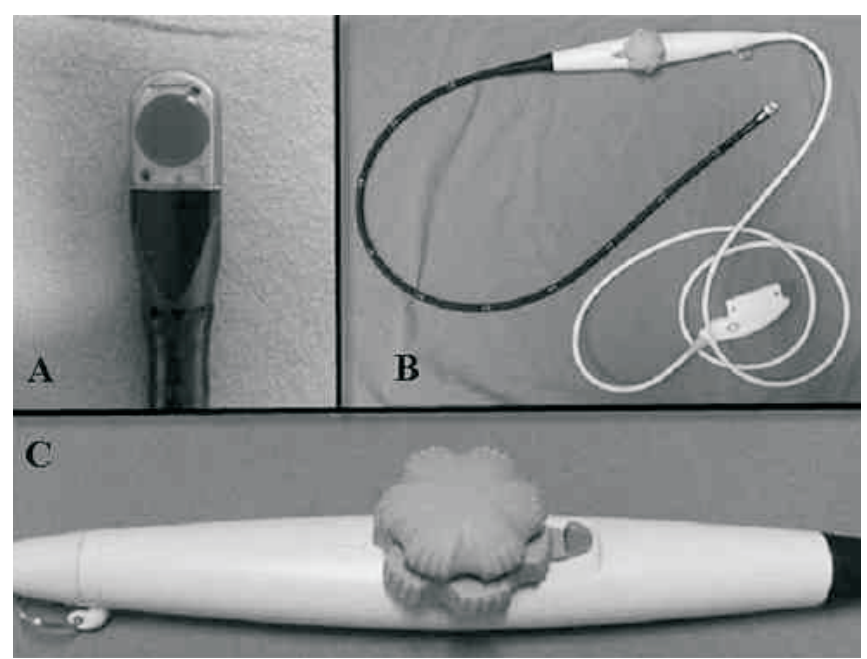

Figure 1 - Transesophageal Echocardiography Probe with a Transducer on its Tip (Vivid i GE Healthcare).

A: transducer, B: probe with connector, C: proximal component.

especially to obtain information on the characteristics of blood flow ${ }^{17}$. This effect represents the sound frequency variation reflected by a mobile surface so that an observer close to the source of emission will observe an increase in the echo frequency, when the reflecting surface approaches him/her or a decrease in frequency, when it moves away. Therefore, the increase or reduction in frequency indicates the movement direction of the reflecting surface. Applying this knowledge to clinical practice one notes that after the emission of ultrasound energy the approximation or distancing of red blood cells from this energy source will determine the frequency variation of echographic waves. By quantifying the frequency variation one calculates the flow velocity. To obtain accurate measurements based on Doppler effect, the ultrasound beam should be parallel to blood flow.

The following are modalities of Doppler effects in echocardiography: pulsatile Doppler, continuous Doppler, color Doppler, and tissue Doppler. Pulsatile Doppler uses only one crystal to send and receive ultrasound pulses of a predetermined frequency (pulse repetition frequency). Quantification of high velocity flows can not be accurately determined by pulsatile Doppler. The maximum velocity obtained with this modality is related to half the pulse repetition frequency, also known as Nyquist limit. Continuous Doppler uses two crystals (one sends and the other receives) to continuously measure blood flow velocity allowing accurate measurement of high velocity blood flow. Color Doppler uses pulsatile Doppler technology to evaluate flow velocity in multiple sites. The movement of blood flow towards the transducer is represented in red, while flow moving in the opposite direction is represented in blue. With rapid acceleration or turbulent flow, we can observe the color green or a mosaic of colors on the monitor. By the superposition of color flow mapping and bidimensional image of the heart, we can visualize the direction and velocity of blood flow. The different Doppler modalities help calculate transvalvular pressure gradients, the area of regurgitant valvular 
orifice, estimate intracavitary pressures, intracardiac shunts, and assess systolic and diastolic function as well as cardiac output ${ }^{18,19}$.

The bidimensional (2D) image is generated from data obtained by electronically scanning the ultrasound beam through the ultrasound field. Because in transesophageal echocardiography the transducer is located in the esophagus or stomach, posterior cardiac structures are closer to the transducer while anterior structures are more distant.

\section{TECHNIQUES OF IMAGE ACQUISITION}

According to the image on echocardiograph screen it is possible to infer the probe positioning in the upper digestive tract (esophagus or stomach). The probe distal tip is flexible and has two control mechanisms that allow anteflexion and retroflexion movements, as well as lateral dislocations. Other movements necessary to better direct the ultrasound beam include going forward or backwards and clockwise and anticlockwise movements. Currently most transducer are multiplane allowing more detailed assessment of cardiac structures since it is possible, with this technology, $0^{\circ}$ and $180^{\circ}$ axial rotations without probe displacement (Figure 2).

The probe has four main positions that allow obtaining most of the echocardiographic cuts necessary for effective intraoperative evaluation. The position of the transducer extremity is oriented taking into account the distance introduced from the upper dental arch. The planes include: upper esophagus $(20-25 \mathrm{~cm})$, middle esophagus $(30-40 \mathrm{~cm})$, transgastric $(40-$ $45 \mathrm{~cm})$, and deep transgastric $(45-50 \mathrm{~cm})$. In each plane, it is possible to obtain several echocardiographic images.

\section{CARE FOR PROBE INSERTION}

Once the decision of using intraoperative TEE is made, it is possible to proceed with inserting the probe into the digestive tract shortly after tracheal intubation and correct fixation of the endotracheal tube. However, to provide better image quality, gastric contents should be aspirated with a gastric tube. Other care should also be taken before insertion of the TEE probe to achieve better safety: the probe should be inspected to determine its structural integrity and cleanliness, controls should be unlocked and a bit blocker should not be forgotten in order to avoid dental damage, and injuries to the tongue or mouth gum. The probe should be lubricated with a hydrosoluble gel before insertion.

The probe should be gently introduced through the posterior oropharynx, without perception of greater resistance, being careful to position the transducer elements anteriorly. Occasionally, a lower jaw traction maneuver is necessary and, in cases of greater difficulty and resistance, insertion may require the aid of a laryngoscope. In some cases, a hyperinflated tracheal tube balloon can hinder its passage.

\section{MAIN ECHOCARDIOGRAPHIC CUTS}

Diagnostic imaging exams have differentiated interobserver degrees of variability, and disparities among observations are directly proportional to the difference in operator qualification and training ${ }^{20}$. This finding, associated with the consistent increased number of intraoperative exams performed in the United States after the qualification effort of anesthesiologists, determined the need to standardize the terms and techniques used, so that observations and reports could have comparison parameters and consequently be useful both in daily practice and clinical research ${ }^{21}$.

In 1999 the American Society of Echocardiography (ASE) along with the Society of Cardiovascular Anesthesiologists (SCA) published guidelines for TEE, with recommendations for a complete and adequate intraoperative transesophageal echocardiography ${ }^{22}$. A systematization of the exam was established including analysis of cardiac cavities, valves, and aorta both with bidimensional (2D) echocardiography and Doppler. Twenty tomographic cut patterns of the heart and great vessels (Figure 3) were established, which should be performed to avoid overlooking any significant changes. The nomenclature respected the transducer position in the digestive tract (upper esophagus, mid esophagus, transgastric, and deep
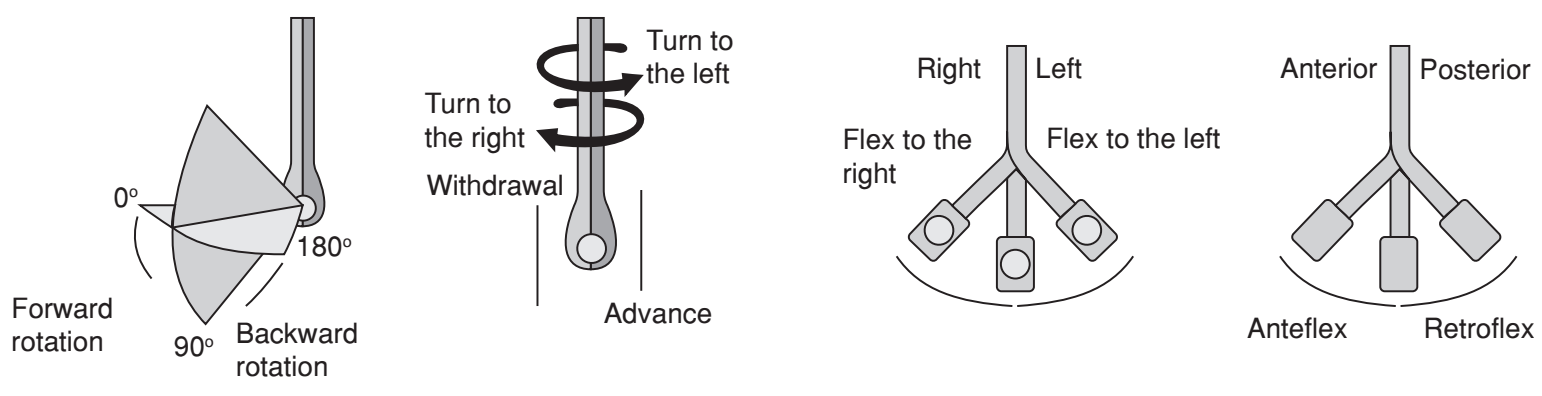

Figure 2 - Movements to Manipulate the Probe and Transducer to Acquire Echocardiographic Images. Adapted from Shanewise et al. ${ }^{22}$. 


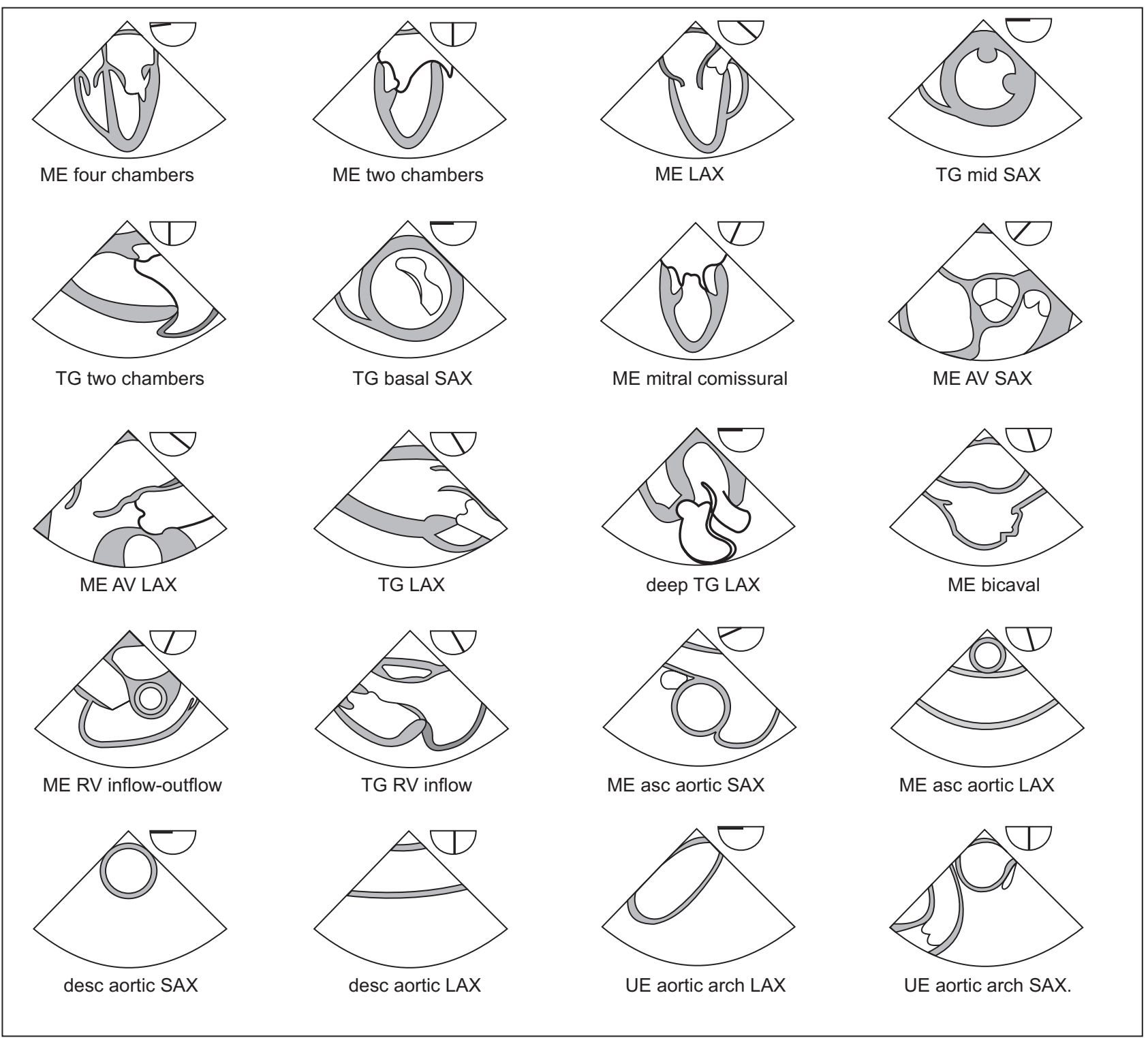

Figure 3 - Main Recommended Cuts for Intraoperative TEE. ME: mid esophagus, TG: transgastric, AV: aortic valve, RV: right ventricle, asc.: ascending, desc.: descending, UE: upper esophagus. Adapted from Shanewise er al. ${ }^{22 .}$

transgastric), description of the image plane (longitudinal and transversal axis), and the main structure evaluated.

The sequence of tomographic cuts has not been established. However, most operators prefer to begin with cuts that most likely will provide relevant information to the clinical case in question, complementing the exam with acquisition of other images. Standardized cuts are usually obtained in most patients, and they determine satisfactory images (Figures 4, 5 and 6). However, due to occasional anatomical variations a complete exam is not always possible.

Good practice demands that at each exam a digital recording of images must be performed in the equipment and whenever possible they must be transferred to a digital media. These images are useful as documentary source, allowing comparison of structures and function in several moments of the procedure (pre-ECC, post-ECC, and immediate and late postoperative periods).

\section{INDICATIONS AND CLINICAL APPLICATIONS}

Even before 1966, ASA and SCA were concerned with the intended use of intraoperative TEE. Right at that year the first guidelines for this purpose were published ${ }^{23}$. At that time 1,884 articles were reviewed and 58 of them were considered relevant to the intraoperative environment. In 2003 another 118 articles were added to the review ${ }^{24}$.

The main indications were grouped into three categories considering the degree of clinical evidence of the method effective benefit (Table I). Class I indications are supported 


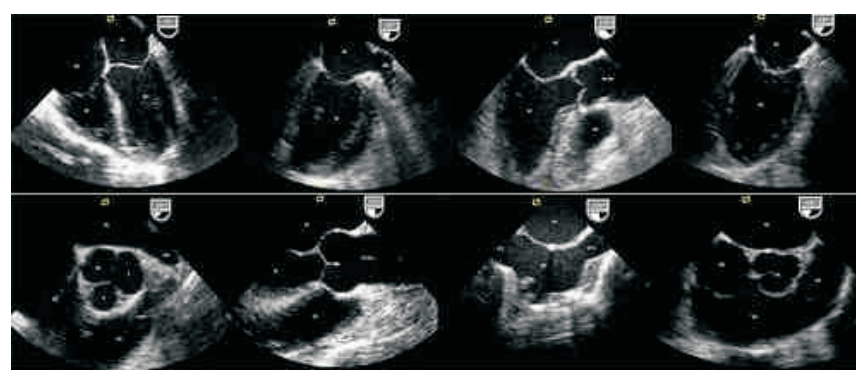

Figure 4 - Main Cuts Obtained Through the Mid Esophagus.

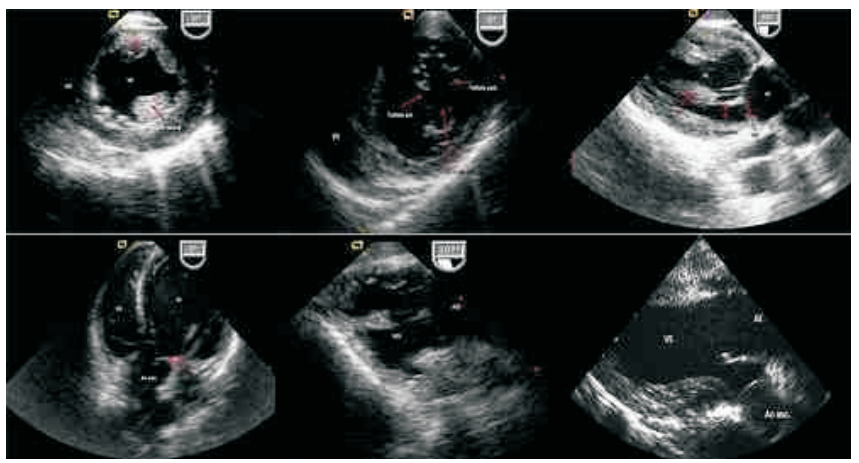

Figure 5 - Main Transgastric Cuts.

by strong evidence or expert opinions, and TEE is frequently useful and indicated. In Class II indications, its use has less evidence and consensus among experts, and it may be useful for clinical improvement of patients. Class III indications presents insufficient evidence with little use and its indication has no consensus.

Recently, through a new guideline ${ }^{25}$, intraoperative transesophageal echocardiography should be performed in every adult patient undergoing open heart surgery (for example, valvular procedures) and procedures in the thoracic aorta. Furthermore, one should take into account its clinical application

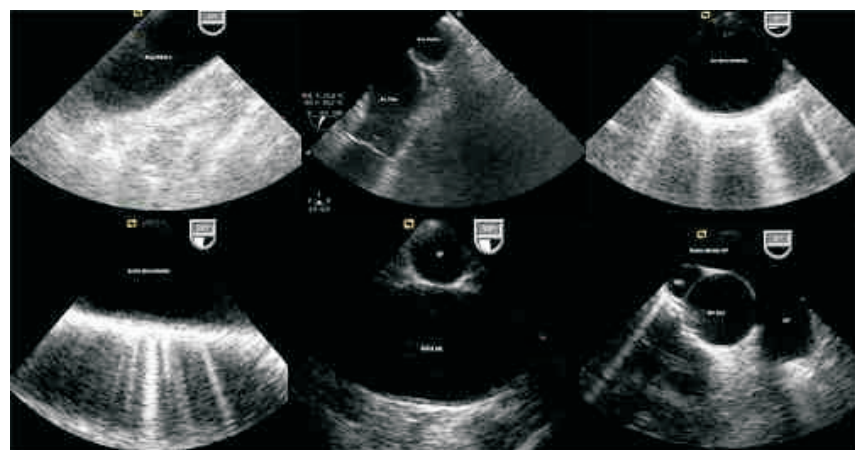

Figure 6 - Cuts to Evaluate the Aorta.

in myocardial revascularization surgeries to confirm and refine the preoperative diagnosis, detect new pathologies, orient the anesthetic and surgical procedure, as well as assess the surgical result.

\section{ASSESSMENT OF HEMODYNAMIC INSTABILITY}

Hemodynamic evaluation by echocardiography represents one of the main benefits of the method, and useful both for etiologic diagnosis of hemodynamic instability (hypovolemia, myocardial depression, pulmonary embolism, and cardiac tamponade) and therapeutic guidance (volume expansion, inotropes, vasodilators, pericardial drainage, etc). On echocardiography we can directly estimate global ventricular contractility ${ }^{26}$ and intracavitary volume ${ }^{27,28}$, as well as other hemodynamic parameters such as: systolic pressure in the pulmonary artery and right ventricle, left atrial pressure, left ventricular (LV) end-diastolic pressure, cardiac output, and ejection fraction. Many of these variables show good correlation when compared to more invasive methods.

Table I - Main Indications for Perioperative TEE 23,24

\begin{tabular}{|c|c|c|}
\hline Class I & Classes Ila e Illb & Class III \\
\hline $\begin{array}{l}\text { Acute hemodynamic instability of unknown } \\
\text { etiology }\end{array}$ & $\begin{array}{l}\text { Risk of myocardial ischemia/ infarction/ } \\
\text { hemodynamic changes }\end{array}$ & Catheter placement (IABP, PAC) \\
\hline Valvular repair & Valvular exchange/ Maze surgery & \\
\hline Repair of hypertrophic cardiomyopathy & $\begin{array}{l}\text { Detection of air embolism/ evaluation of } \\
\text { myocardial perfusion }\end{array}$ & $\begin{array}{l}\text { Surgical repair of non-complicated ostio } \\
\text { secundum IAC }\end{array}$ \\
\hline \multicolumn{3}{|l|}{ Endocarditis } \\
\hline Ross surgery & $\begin{array}{l}\text { Evaluation of pericardiectomy/ pulmonary } \\
\text { embolectomy }\end{array}$ & $\begin{array}{l}\text { Monitoring of embolism in orthopedic } \\
\text { surgeries }\end{array}$ \\
\hline $\begin{array}{l}\text { Aortic aneurisms and dissections with } \\
\text { suspicion of aortic insufficiency }\end{array}$ & $\begin{array}{l}\text { Aortic aneurisms and dissections without } \\
\text { suspicion of aortic insufficiency }\end{array}$ & \\
\hline $\begin{array}{l}\text { Evaluation for pericardial procedures } \\
\text { (pericardial window) }\end{array}$ & Cardiac trauma & \\
\hline
\end{tabular}

ECC: extracorporeal circulation, IABP: intra-aortic balloon pump, PAC: pulmonary artery catheter. 


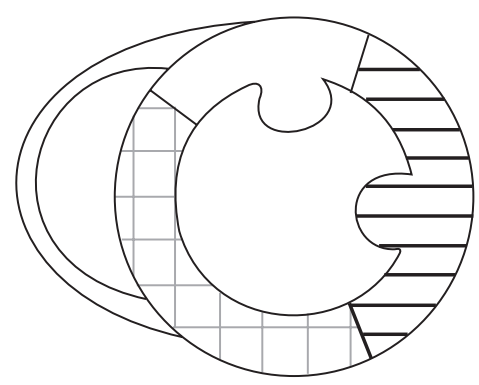

Medial Transgastric Transversal Cut

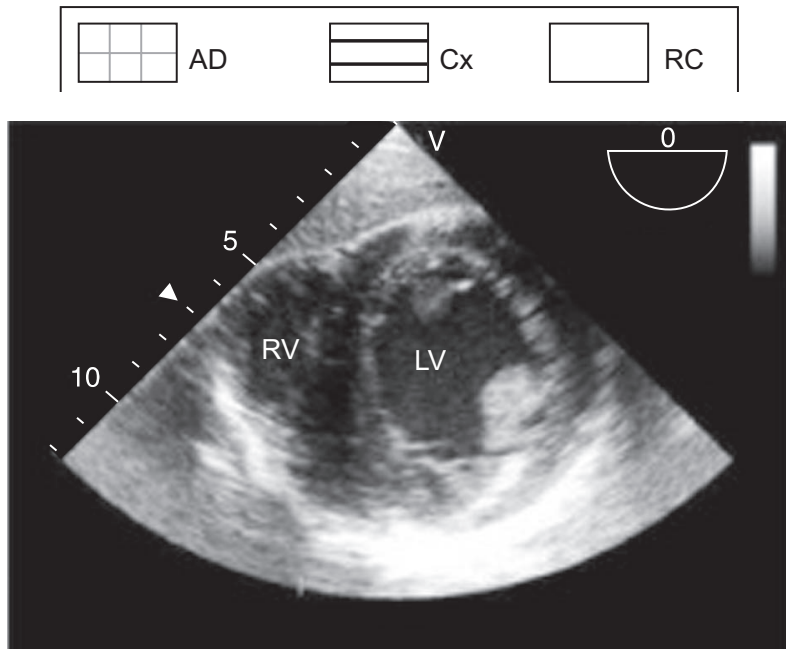

Figure 7 - Medial Transgastric Transversal Cut of the Left Ventricle Showing Areas of the Myocardium Irrigated by the Respective Coronary Arteries. AD: anterior descending; Cx: circumflex; RC: right coronary artery.

Transesophageal echocardiography is superior to pulmonary artery catheter in diagnosing acute hemodynamic changes. Reichert et al. ${ }^{29}$ investigated 60 patients during the postoperative period of cardiac surgery with persistent and significant hypotension. In 30 of these patients, the etiology of hypotension was changed by TEE avoiding reoperation in $16.6 \%$ of cases, and in two patients an urgent exploratory thoracotomy was indicated. Bergquist et al. ${ }^{30}$ reported that TEE was the most important monitor in evaluating volume of patients undergoing myocardial revascularization. When all types of interventions are considered, administration of fluids was more influenced by TEE (30\%), followed by pulmonary artery catheter $(7 \%)$.

\section{MONITORING MYOCARDIAL ISCHEMIA}

Detection and localization of changes in segmental contractility of LV are the objective of echocardiography in monitoring myocardial ischemia. These changes are seen early $(<1 \mathrm{mi}-$ nute) after the onset of inadequate myocardial perfusion ${ }^{31}$. Analysis of LV contractility depends on the visual assessment of myocardial width and movements during systole. Areas that do not show increased thickness during systole or that do not move toward the center of the left ventricular cavity show changes in segmental contractility. With worsening of myocardial oxygen delivery-consumption ratio, segmental changes occur gradually, which range from mild to severe hypokinesia, akinesia, and finally dyskinesia. It has been demonstrated that TEE is the most sensitive and early monitoring method in the diagnosis of intraoperative myocardial ischemia ${ }^{32}$. The transversal transgastric cut, at the level of papillary muscles in which we can visualize the territories irrigated by the three main coronary arteries, is used more commonly for monitoring segmental LV changes (Figure 7).

However, several studies insist on the relevance of TEE in detecting and modifying the therapeutic conduct, especially in differentiating ischemia from infarction and stunning. Cwajg et al. ${ }^{33}$ investigated the end-diastolic width of the ventricular wall in 45 patients undergoing myocardial revascularization, and they concluded that this measurement is an important marker, comparable to T1-201 scintigraphy. They verified that values equal or lower than $0.6 \mathrm{~cm}$ exclude the possibility of functional recovery. The differentiation between ischemia and stunning may be essential for prognosis, especially in surgeries without extracorporeal circulation; therefore, detection of segmental alterations of the ventricular wall in the immediate postoperative period is predictive of incomplete revascularization.

\section{VALVULAR ASSESSMENT}

The method is very sensitive in the anatomical evaluation of the valves, allowing diagnosing the mechanisms of valvular dysfunction and quantifying the degree of dysfunction, data that influence significantly decision making regarding surgical treatment. It also allows the immediate assessment of the quality of treatment provided. Sheikh et al. ${ }^{34}$ observed 154 patients who underwent valvular surgeries detecting a change in surgical conduct during the procedure in $19 \%$ of cases, and in 10 patients $(6 \%)$ the surgical result was inadequate indicating the need for immediate reoperation. When evaluating 2,076 patients undergoing mitral valve repaire, Brown et al. diagnosed anterior systolic movement in $8.4 \%$ of cases ${ }^{35}$, and TEE was fundamental not only in the diagnosis, but also to orient treatment (volume, beta-blockers, and vasoconstriction with phenylephrine). Four of these patients required immediate reoperation due to important obstruction of the left ventricular outlet. The diagnosis of cardiac prosthesis dysfunction is another relevant application of TEE ${ }^{36,37}$.

\section{DETECTION OF AORTIC ATHEROMATOUS PLAQUES}

Focal neurologic lesion (stroke) is one of the most feared complications after cardiac surgery. Although it has a multifactorial etiology, the presence of atheromatous plaques in the aorta has important implications. In 130 patients with more than 65 years of age who underwent myocardial revascularization with $\mathrm{ECC}$, the presence of protruding atheromatous 
plaques proved to be an independent risk factor for strokes ${ }^{38}$. Transesophageal echocardiography has an important role in detecting these plaques and is more sensitive than aortic palpation performed by the surgeon ${ }^{39,40}$. Non-visualization of the distal portion of the ascending aorta and proximal aortic arch, which is commonly used by surgeons for placement of an arterial cannula is one of the limitations of TEE. In this area there is an acoustic shadow produced by the interposition of the trachea and the left bronchus. Recently, the use of epiaortic echocardiography ${ }^{41}$ fulfilled this deficiency of TEE being a strategic tool to reduce intraoperative cerebral embolism. The presence of protruding plaques with mobile components may collaborate for the change in surgical strategy, for example, change in the technique of arterial cannula placement, use of arterial cannulas with protection filters, and even surgery without ECC if the procedure allows it ${ }^{42}$.

\section{AORTIC DISSECTION}

The accuracy of transesophageal echocardiography in the diagnosis of aortic dissections is comparable to that of computed tomography and MRI ${ }^{43}$. It is an important method to identify intimal flap (Figure 8), the site of entry and reentry, differentiation between the true and false lumen, and detection of intramural thrombus ${ }^{44}$. The differentiation between true and false lumen can be difficult in some patients. The true lumen expands during systole and decreases during diastole. In general, the false lumen shows a spontaneous echo contrast and thrombus. Blood flow in true lumen and slowing or absence of flow in false lumen may be observed on color Doppler. In many cases the false lumen is greater than the true lumen. Transesophageal echocardiography can also evaluate the complications of dissection including pericardial effusion, presence and severity of aortic insufficiency, in addition to changes in segmental contractility due to coronary involvement.

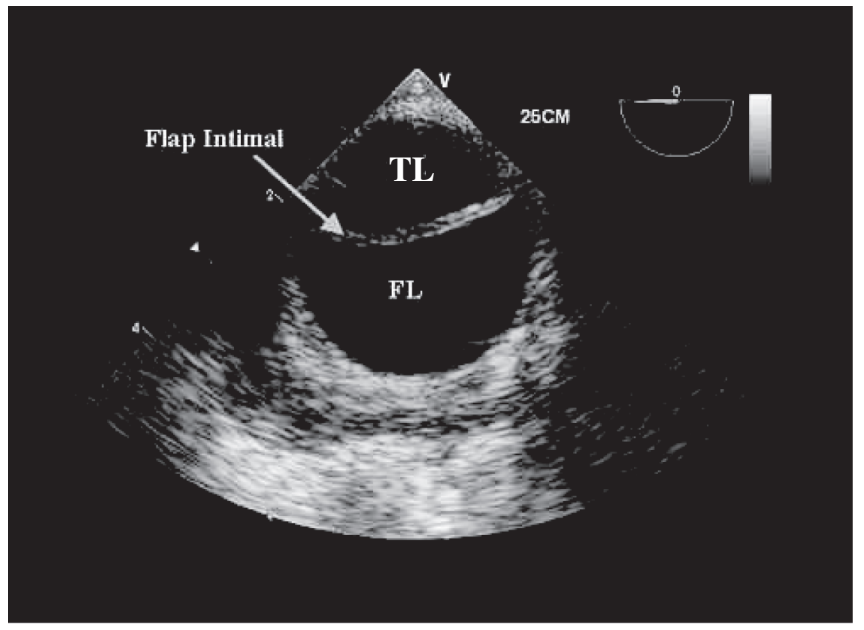

Figure 8 - Transversal Cut of the Descending Aorta Showing the Dissection Line with an Intimal Flap.

TL: True lumen, FL: False lumen.

\section{CONGENITAL CARDIOPATHY}

Technological advances made possible the availability of pediatric probes, which was fundamental for the use of TEE in surgeries for congenital cardiopathy in children especially due to its aid in diagnosing previously undetected anomalies on transthoracic echocardiography, as well as improving the specification of the type of lesion, direction of shunts, size of cavities, degree of dysfunction, and other associated anomalies ${ }^{45}$. Stevenson et al. ${ }^{46}$ investigated 230 patients who underwent surgical correction of congenital cardiopathies observing that on TEE $7 \%$ of those patients had residual cardiac defects at the end of the procedure, which determined new interventions for correction.

\section{DETECTION OF INTRACARDIAC AIR}

Transesophageal echocardiography is a sensitive method for detecting the presence of intracardiac air and aiding its removal before removal of extracorporeal circulation. Air embolism of left cavities may cause neurologic injury, transient ventricular dysfunction, and arrhythmias. The presence of transient right ventricular dysfunction upon removal of ECC due to air embolism to the right coronary artery is a common finding in air embolism ${ }^{47}$. The sites in which air accumulates more often include: left ventricle apex, left atrium, left atrial appendage, and pulmonary veins.

\section{OTHER USEFUL ASSESSMENTS}

The following are also part of the repertoire of potential benefits of TEE in cardiac surgeries: detection of intracavitary thrombi, aid positioning intravascular cannulas and catheters (intra-aortic balloon pump, central venous catheter, inferior vena cava cannula ${ }^{48}$, and cannula in the venous coronary sinus), pulmonary embolism ${ }^{49}$, in implantation and evaluation of circulatory assistance devices ${ }^{50}$, and verification of anastomosis in cardiac transplants.

\section{CONTRAINDICATIONS}

On pre-anesthetic evaluation, one can investigate the presence of occasional contraindications to the examination and consider them along with anesthesia planning. The main contraindications are related to pathologies of the oropharynx, esophagus, or stomach. Table II shows the absolute and relative contraindications of TEE. Although esophageal varices are considered a relative contraindication, patients with esophageal varices grade 1 or 2 without recent episodes of hemorrhage can safely undergo TEE, but transgastric cuts should be avoided ${ }^{51}$. 
Table II - Absolute and Relative Contraindications of TEE

\begin{tabular}{l}
\hline Absolute \\
Esophageal stenosis \\
Large esophageal diverticuli \\
Esophageal tumors \\
Recent esophageal suture \\
Known esophageal interruptions \\
Relative \\
Symptomatic hiatal hernia \\
Severe esophagitis \\
Coagulopathies \\
Esophageal varices \\
Non-diagnosed gastrointestinal hemorrhage \\
\hline
\end{tabular}

\section{COMPLICATIONS}

Transesophageal echocardiography is a semi-invasive procedure with low risk of complications. However, the anesthesiologist must be aware of the types of complications and their predisposing factors in order to prevent their occurrence 52,53. In a retrospective study, Kallmeyer et al. ${ }^{54}$ evaluated 7,200 patients who underwent cardiac surgery observing a morbidity of $0.2 \%$ and no deaths. In another multicenter study 55 with 10,218 patients undergoing TEE only one fatal case was observed due to esophageal perforation. Complications resulting from intraoperative TEE are related to direct trauma of the airways or esophagus or to indirect effects (Table III). In children, even a probe of adequate gauge may cause obstruction of the airways distal to the endotracheal tube or compress the descending aorta ${ }^{56}$.
Table III - Complications of TEE

\begin{tabular}{l}
\hline Direct trauma \\
Lacerations \\
Burns \\
Esophageal bleeding \\
Dysphagia \\
Vocal cord paralysis \\
Indirect effects \\
Hemodynamic changes \\
Hypertension \\
Hypotension \\
Arrhythmias \\
Pulmonary changes \\
Bronchospasm \\
Interpretation error \\
Negligence in patient care
\end{tabular}

\section{CONCLUSIONS}

Transesophageal echocardiography is a safe and low risk imaging examination that has been used for a few decades in intra- and postoperative periods of cardiac surgeries. The method is superior to other cardiovascular monitors due to detailed real-time anatomical and physiologic information. Transesophageal echocardiography is able to provide data that will influence surgical strategy and anesthetic conduct, as well as allowing the immediate evaluation of surgical results. The main limitations to its routine use are related to the equipment cost and the need for a professional with adequate training. Once qualified, the anesthesiologist expands his role in perioperative medicine, providing vital clinical information for anesthetic-surgical procedure. Based on all the benefits presented in this article and in view of the low risk, the authors corroborate the current guidelines for the use of intraoperative TEE in patients undergoing cardiac surgeries. 


\section{REFERÊNCIAS / REFERENCES}

01. Johnson ML, Holmes $\mathrm{JH}$, Spangler RD et al. Usefulness of echocardiography in patients undergoing mitral valve surgery. J Thorac Cardiovasc Surg, 1972;64:922-934.

02. Matsumoto M, Oka Y, Strom J et al. - Application of transesophageal echocardiography to continuous intraoperative monitoring of left ventricular performance. Am J Cardiol 1980;46:95-105.

03. Vegas A, Meineri M - Three-dimensional transesophageal echocardiography is a major advance for intraoperative clinical management of patients undergoing cardiac surgery: a core review. Anesth Analg, 2010;110:1548-1573.

04. Kwak J, Andrawes M, Garvin S et al. - 3D transesophageal echocardiography: a review of recent literature 2007-2009. Curr Opin Anaesthesiol, 2010;23: 80-88.

05. Seward JB, Khandheria BK, Freeman WK et al. - Multiplane transesophageal echocardiography: image orientation, examination technique, anatomic correlations, and clinical applications. Mayo Clin Proc, 1993;68:523-551.

06. Eltzschig HK, Rosenberger $\mathrm{P}$, Loffler $\mathrm{M}$ et al. - Impact of intraoperative transesophageal echocardiography on surgical decisions in 12,566 patients undergoing cardiac surgery. Ann Thorac Surg, 2008;85:845852.

07. Schroder JN, Williams ML, Hata JA et al. - Impact of mitral valve regurgitation evaluated by intraoperative transesophageal echocardiography on long-term outcomes after coronary artery bypass grafting. Circulation, 2005;112:293-298.

08. Couture P, Denault AY, McKenty $S$ et al. - Impact of routine use of intraoperative transesophageal echocardiography during cardiac surgery. Can J Anaesth, 2000;47:20-26.

09. Eltzschig HK, Rosenberger P, Loffler M, et al. - Impact of intraoperative transesophageal echocardiography on surgical decisions in 12,566 patients undergoing cardiac surgery. Ann Thorac Surg, 2008;85:845-852.

10. Minhaj M, Patel K, Muzic D et al. - The effect of routine intraoperative transesophageal echocardiography on surgical management. J Cardiothorac Vasc Anesth, 2007;21:800-804.

11. Fanshawe $M$, Ellis $C$, Habib $S$ et al. - A retrospective analysis of the costs and benefits related to alterations in cardiac surgery from routine intraoperative transesophageal echocardiography. Anesth Analg, 2002;95:824-827.

12. Cahalan MK, Abel M, Goldman M et al. - American Society of Echocardiography and Society of Cardiovascular Anesthesiologists task force guidelines for training in perioperative echocardiography. Anesth Analg, 2002;94:1384-1388.

13. Beique $F$, Ali $M$, Hynes $M$ et al. - Canadian guidelines for training in adult perioperative transesophageal echocardiography. Recommendations of the Cardiovascular Section of the Canadian Anesthesiologists' Society and the Canadian Society of Echocardiography. Can J Anaesth, 2006;53:1044-1060.

14. Mathew JP, Glas K, Troianos CA et al. - ASE/SCA recommendations and guidelines for continuous quality improvement in perioperative echocardiography. Anesth Analg, 2006;103:1416-1425.

15. Kossoff $\mathrm{G}-$ Basic physics and imaging characteristics of ultrasound. World J Surg, 2000;24:134-142.

16. Wells PN - Physics and engineering: milestones in medicine. Med Eng Phys, 2001;23:147-153.

17. Lawrence JP - Physics and instrumentation of ultrasound. Crit Care Med, 2007; 35(8/suppl):s314-322.

18. Quiñones MA, Otto CM, Stoddard $M$ et al. - Recommendations for quantification of Doppler echocardiography: a report from the Doppler Quantification Task Force of the Nomenclature and Standards Committee of the American Society of Echocardiography. J Am Soc Echocardiogr, 2002;15:167-184.

19. Poelaert Jl, Shupfer G - Hemodynamic monitoring utilizing transesophageal echocardiography: the relationships among pressure, flow, and function. Chest, 2005;127:379-390.
20. Vandenberg BF, Lindower PD, Lewis J et al. - Reproducibility of left ventricular measurements with acoustic quantification: the influence of training. Echocardiography, 2000;17:631-637.

21. Lang RM, Bierig M, Devereux RB et al. - Recommendations for chamber quantification: a report from the American Society of Echocardiography's Guidelines and Standards Committee and the Chamber Quantification Writing Group, developed in conjunction with the European Association of Echocardiography, a branch of the European Society of Cardiology. J Am Soc Echocardiogr, 2005;18:14401463.

22. Shanewise JS, Cheung AT, Aronson S et al. - ASE/SCA guideline for performing a comprehensive intraoperative multiplane transesophageal echocardiography examination: recommendations of the American Society of Echocardiography Council for Intraoperative Echocardiography and the Society of Cardiovascular Anesthesiologists Task Force for Certification in Perioperative Transesophageal Echocardiography. Anesth Analg, 1999;89:870-884.

23. Thys $D$, Abel $M$, Bollen $B$ et al. - Practice guidelines for perioperative transesophageal echocardiography. A report by the American Society of Anesthesiologists and the Society of Cardiovascular Anesthesiologists Task Force on Transesophageal Echocardiography. Anesthesiology, 1996;84:986-1006.

24. Alpert JS, Anderson JL, Faxon DP, et al. - ACC/AHA/ASE 2003 guideline update for the clinical application of echocardiography. JACC, 2003;42:954-970.

25. Thys DM, Abel MD, Brooker FR, et al. - Practice guidelines for perioperative transesophageal echocardiography. Anesthesiology, 2010;112:1084-1096.

26. London MJ - Assessment of left ventricular global systolic function by transesophageal echocardiography. Ann Card Anaesth, 2006;9:157163.

27. Hofer CK, Ganter MT, Rist A et al. - The accuracy of preload assessment by different transesophageal echocardiographic techniques in patients undergoing cardiac surgery. J Cardiothorac Vasc Anesth, 2008;22:236-242.

28. De Simone R, Wolf I, Mottl-Link S et al. - Intraoperative assessment of right ventricular volume and function. Eur J Cardiothorac Surg, 2005;27:988-993.

29. Reichert CL, Visser CA, Koolen JJ et al. - Transesophageal echocardiography in hypotensive patients after cardiac operations. Comparison with hemodynamic parameters. J Thorac Cardiovasc Surg, 1992;104:321-326.

30. Bergquist $\mathrm{BD}$, Bellows $\mathrm{WH}$, Leung JM - Transesophageal echocardiography in myocardial revascularization: II. Influence on intraoperative decision-making. Anesth Analg, 1996;82:1139-1145.

31. Labovitz AJ, Lewen MK, Kern $M$ et al. - Evaluation of left ventricular systolic and diastolic dysfunction during transient myocardial ischemia produced by angioplasty. J Am Coll Cardiol, 1987;10:748-755.

32. Shanewise JS - How to reliably detect ischemia in the intensive care unit and operating room. Semin Cardiothorac Vasc Anesth, 2006;10:101-109.

33. Cwajg JM, Cwajg E, Nagueh SF et al. - End-diastolic wall thickness as a predictor of recovery of function in myocardial hibernation: relation to rest-redistribution T1-201 tomography and dobutamine stress echocardiography. J Am Coll Cardiol, 2000;35:1152-1161.

34. Sheikh KH, de Bruijn NP, Rankin JS et al. - The utility of transesophageal echocardiography and Doppler color flow imaging in patients undergoing cardiac valve surgery. J Am Coll Cardiol, 1990;15:363372.

35. Brown ML, Abel MD, Click RL et al. - Systolic anterior motion after mitral valve repair: is surgical intervention necessary? J Thorac Cardiovasc Surg, 2007;133:136-143.

36. Ionescu A, Fraser AG, Butchart EG et al. - Prevalence and clinical significance of incidental paraprosthetic valvar regurgitation: a prospective study using transoesophageal echocardiography. Heart, 2003;89:1316-1321.

37. Zoghib WA, Chambers JB, Dumesnil JG et al. - Recommendations for evaluation of prosthetic valves with echocardiography and doppler ultrasound. J Am Soc Echocardiogr, 2009;22:975-1014. 
38. Katz ES, Tunick PA, Rusinek $\mathrm{H}$ et al. - Protruding aortic atheromas predict stroke in elderly patients undergoing cardiopulmonary bypass: experience with intraoperative transesophageal echocardiography. J Am Coll Cardiol, 1992;20:70-77.

39. Suvarna S, Smith A, Stygall J et al. - An intraoperative assessment of the ascending aorta: a comparison of digital palpation, transesophageal echocardiography, and epiaortic ultrasonography. J Cardiothorac Vasc Anesth, 2007;21:805-809.

40. Whitley WS, Glas KE - An argument for routine ultrasound screening of the thoracic aorta in the cardiac surgery population. Semin Cardiothorac Vasc Anesth, 2008;12:290-297.

41. Glas KE, Swaminathan M, Reeves ST et al. - Guidelines for the performance of a comprehensive intraoperative epiaortic ultrasonographic examination: recommendations of the American Society of Echocardiography and the Society of Cardiovascular Anesthesiologists; endorsed by the Society of Thoracic Surgeons. J Am Soc Echocardiogr, 2007;20:1227-1235.

42. Misha M, Malhotra R, Karlekar A et al. - Propensity case-matched analysis of off-pump versus on-pump coronary artery bypass grafting in patients with atheromatous aorta. Ann Thorac Surg, 2006;82:608614.

43. Shiga T, Wajima Z, Apfel CC et al. - Diagnostic accuracy of transesophageal echocardiography, helical computed tomography, and magnetic resonance imaging for suspected thoracic aortic dissection: systematic review and meta-analysis. Arch Intern Med, 2006;166:1350-1356.

44. Eltzchig HK, Rosenberger P, Lekowski Jr RW et al. - Role of transesophageal echocardiography patients with suspected aortic dissection. J Am Soc Echocardiogr, 2005;18:1221.

45. Bettex DA, Schmidlin D, Bernath MA et al. - Intraoperative transesophageal echocardiography in pediatric congenital cardiac surgery: a two-center observational study. Anesth Analg, 2003;97:1275-82.

46. Stevenson JG, Sorensen GK, Gartman DM et al. - Transesophageal echocardiography during repair of congenital cardiac defects: identification of residual problems necessitating reoperation. J Am Soc Echocardiogr, 1993;6:356-365.

47. Chandraratna A, Ashmeg A, Chamsi Pasha H - Detection of intracoronary air embolism by echocardiography. J Am Soc Echocardiogr, 2002;15:1015-1017.

48. Kirkeby-Garstad I, Tromsdal A, Sellevold OFM et al. - Guiding surgical cannulation of the inferior vena cava with transesophageal echocardiography. Anesth Analg, 2003;96:1288-1293.

49. Rosenberger P, Shernan SK, Body SC et al. - Utility of intraoperative transesophageal echocardiography for diagnosis of pulmonary embolism. Anesth Analg, 2004;99:12-16.

50. Chumnanvej S, Wood MJ, MacGillivray TE et al. - Perioperative echocardiographic examination for ventricular assist device implantation. Anesth Analg, 2007;105:583-601.

51. Spier BJ, Larue SJ, Teelin TC et al. - Review of complications in a series of patients with known gastro-esophageal varices undergoing transesophageal echocardiography. J Am Soc Echocardiogr, 2009;22:396-400
52. Côté G, Denault A - Transesophageal echocardiography-related complications. Can J Anesth, 2008;55:622-647.

53. Piercy M, McNicol L, Dinh DT et al. - Major complications related to the use of transesophageal echocardiography in cardiac surgery. J Cardiothorac Vasc Anesth, 2009;23:62-65.

54. Kallmeyer IJ, Collard CD, Fox JA et al. - The safety of intraoperative transesophageal echocardiography: a case series of 7200 cardiac surgical patients. Anesth Analg, 2001;92:1126-1130.

55. Daniel WG, Erber R, Kasper W et al. - Safety of transesophageal echocardiography. A multicenter survey of 10419 examinations. Circulation, 1991;83:817-821.

56. Lunn RJ, Oliver WC Jr, Hagler DJ et al. - Aortic compression by transesophageal echocardiographic probe in infants and children undergoing cardiac surgery. Anesthesiology, 1992;77:587-590.

Resumen: Galhardo Jr C, Botelho ESL, Diego LAS - Monitorización Intraoperatoria con Ecocardiografía Transesofágica en Cirugía Cardíaca.

Justificativa y objetivos: Desde su introducción clínica en la década del 80, la ecocardiografía transesofágica (ETE) intraoperatoria ha venido siendo uno de los mayores avances en la anestesia cardíaca moderna. Es una técnica semiinvasiva, que permite una visualización directa y rápida de la anatomía estructural del corazón y de los grandes vasos, además de aportar a la evaluación hemodinámica y funcional del sistema cardiovascular. Así, se ha convertido en un importante monitor en el auxilio diagnóstico de patologías cardíacas e intervenciones anestésico-quirúrgicas. El objetivo del artículo, es realizar una revisión abarcadora sobre la utilización de la ETE en el intraoperatorio de cirugía cardíaca.

Contenido: El artículo aborda algunos aspectos relacionados con la física del ultrasonido, con las técnicas para la obtención de las imágenes, los cortes ecocardiográficos más utilizados en el intraoperatorio, las indicaciones y las principales aplicaciones clínicas del método, además de las contraindicaciones y complicaciones.

Conclusiones: La ETE intraoperatoria es un método de monitorización cardiovascular seguro y útil en la formulación del plan quirúrgico, en la orientación de intervenciones hemodinámicas y en la evaluación inmediata del resultado operatorio. El anestesiólogo, una vez habilitado para la utilización del método, amplía su rol en el contexto de la medicina perioperatoria, suministrando informaciones clínicas que son imprescindibles para la consecución del acto anestésico quirúrgico en cirugía cardíaca.

Descriptores: CIRUGÍA, Cardíaca, Cuidados preoperatorios; EXAMENES DIAGNÓSTICOS: Ecocardiografía transesofágica; MONITORIZACIÓN. 